\title{
MÍDIAS SOCIAIS E NEGÓCIOS: UM ESTUDO DELPHI
}

\author{
SOCIAL MEDIA AND BUSINESS: A DELPHI STUDY
}

\section{MÍDIAS SOCIALES Y NEGOCIOS: UN ESTUDIO DELPHI}

\section{Bernardo Serra}

Mestrando em Administração pela Universidade de São Paulo - USP

Coordenador técnico In Company na HSM Educação

E-mail: bernardoserra@outlook.com (Brasil)

\section{José Eduardo Storopoli}

Doutorando do Programa de Pós Graduação em Administração da Universidade Nove de Julho PPGA/UNINOVE

Professor de Administração da Universidade Nove de Julho - UNINOVE

E-mail: josees@uninove.br (Brasil)

\section{Claudia Frias Pinto}

Mestranda do Programa de Mestrado Profissional em Administração - Gestão de Projetos da Universidade Nove de Julho - PMPA-GP/UNINOVE

E-mail: claudia.frias.pinto@gmail.com (Brasil)

\section{Fernando Ribeiro Serra}

Doutor em Engenharia pela Pontifícia Universidade Católica do Rio de Janeiro - PUC/RJ

Professor do Programa de Pós Graduação em Administração da Universidade Nove de Julho PPGA/UNINOVE

E-mail: fernandoars@uninove.br (Brasil) 


\title{
MÍDIAS SOCIAIS E NEGÓCIOS: UM ESTUDO DELPHI
}

\section{RESUMO}

As empresas, para chegarem ao seu público, recorrem a ferramentas atuais de comunicação e interação online, como as mídias sociais. Neste artigo pretendemos entender se, e de que forma, as empresas adotarão e utilizarão as mídias sociais no Brasil em 2015. Para traçar este cenário usamos o método delphi. Entrevistamos doze especialistas e, com base nas suas respostas e em documentação secundária, elaborámos o cenário. Os resultados mostram uma evolução crescente, ou seja, as empresas tenderão a adotar e usar cada vez mais as mídias sociais, como uma ferramenta de relacionamento, divulgação da empresa e canal de vendas. Concluimos o artigo com sugestões para pesquisas futuras.

Palavras-chave: Mídias Sociais; Negócios; Estudo Delphi.

\section{SOCIAL MEDIA AND BUSINESS: A DELPHI STUDY}

\begin{abstract}
Firms, in order to achieve their consumer's target, resort to communications tools and online interactions, such as social media. In this study, we propose to comprehend how firms will adopt and utilize social media in Brazil in 2015. In order to assess a scenario we employ the delphi method, in which twelve specialists were interviewed. Based on their responses, the results show that there is a rising trend, that is, firms tend to adopt and increasingly use social media as a networking tool, as publicity and as a sales channel. We conclude with suggestions for future research.
\end{abstract}

Keywords: Social Media; Business; Delphi Study. 


\section{MÍDIAS SOCIALES Y NEGOCIOS: UN ESTUDIO DELPHI}

\section{RESUMEN}

A las empresas a llegar a su público, que utilizan las actuales herramientas de comunicación e interacción en línea, como las redes sociales. Este artículo tiene como objetivo comprender si, y cómo, las empresas adoptan y utilizan las redes sociales en Brasil en 2015. Para trazar este escenario se utiliza el método Delphi. Con doce expertos y, sobre la base de sus respuestas y la documentación secundaria, prepararon el escenario. Los resultados muestran una tendencia al alza, es decir, las empresas tienden a adoptar y utilizar cada vez más los medios sociales como una herramienta de creación de redes, difusión de la compañía y canal de ventas. Concluimos el artículo con sugerencias para la investigación futura.

Palabras-clave: Mídias Sociales; Negocios; Estudios Delphi. 


\section{INTRODUÇÃO}

Nas últimas décadas houve uma grande evolução tecnológica, surgindo novas formas de comunicação, como a comunicação online e novas ferramentas de comunicação, como as mídias sociais. As mídias sociais são os sistemas de comunicação online e interação social mais usados na internet, sendo que mais de 2 bilhões de pessoas são usuárias de alguma delas (QUALMAN, 2011). Muitas empresas no Brasil as utilizam como ferramenta de comunicação e divulgação online, tentando alcançar mais rápido e de forma mais eficaz o seu público alvo. No entanto, apesar dos esforços, muitas vezes essas empresas não sabem como abordar este público (BERTHON ET AL., 2007), ou como lidar com as oportunidades e desafios que as novas mídias representam (KAPLAN e HAENLEIN, 2010).

Há cerca de trinta anos que se estudam as estruturas das relações sociais e a sua influência na sociedade (GRANOVETTER, 1985) e no contexto organizacional. As relações sociais têm impacto nas empresas, por isso as empresas e os seus gestores devem conhecer o contexto social em que estão inseridos, para que consigam interagir com o seu público de forma mais eficiente. As empresas e os gestores devem selecionar os tipos de mídias onde processerão as informações (DAFT, LENGEL e TREVINO, 1987; LENGEL e DAFT, 1988). As mídias sociais permitem que as empresas se relacionem com o seu público de forma direta, a custos relativamente baixos e de forma mais eficiente que outros meios de comunicação tradicionais (KAPLAN e HAENLEIN, 2010). As ações de marketing em mídias sociais aumentam o valor da marca de uma empresa (KIM e KO, 2012), e ajudam a marca a expandir a sua atuação, deixando de ser uma atuação física e regional para uma atuação virtual e global (BRUHN, SCHOENMUELLER e SCHAFFER, 2012).

Em países como os Estados Unidos existem publicações sobre as mídias sociais (BERTHON ET AL., 2007; AVERY e FOURNIER, 2011; WEINBERG e PEHLIVAN, 2011), mas no Brasil o número de pesquisas sobre este assunto é escassa, principalmente quanto ao uso que as empresas fazem das mídias sociais. As pesquisas existentes no país são, na sua maioria, resultados de levantamentos de consultorias ou de empresas (DELOITTE, 2010). Estas pesquisas têm um âmbito essencialmente regional, são em setores específicos, e mostram apenas o que acontece nas mídias sociais no Brasil e não quem são os seus usuários e as motivações para o uso. Estas pesquisas também não abordam as tendências futuras do uso das mídias sociais. Neste artigo procuramos responder às seguintes questões: As empresas brasileiras usam as midias sociais no seu quotidiano? Com que finalidade? Até 2015, as empresas brasileiras irão adotar e utilizar as mídias sociais? Qual é a evolução, a tendência? 
Neste artigo apresentamos um cenário para tentar entender qual a evolução e que utilização as empresas brasileiras farão das mídias sociais em 2015. Para elaborar este cenário usamos o método delphi, que é um instrumento que realiza análises qualitativas e projeções de tendências futuras, consolidando a opinião sobre tendências futuras de um painel de especialistas (WRIGHT e GIOVINAZZO, 2000). Começamos por recolher, através de questionários, as opiniões de doze especialistas e acadêmicos do setor. Em seguida analisamos quantitativa e qualitativamente estas opiniões e, por fim, elaboramos um cenário com as tendências futuras.

Os resultados mostram que as empresas brasileiras tenderão a usar as mídias sociais em 2015. Estima-se que praticamente todas as grandes empresas brasileiras irão aderir às mídias sociais, assim como cerca de metade das médias empresas e as principais ferramentas serão o Facebook e o YouTube. Os principais motivos para a adoção dessas mídias serão devido ao fácil acesso e terá como principais usos uma ferramenta de relacionamento, um meio para divulgação promocional, um canal de atendimento, um acesso ao público alvo e um canal de venda. Como barreiras ao uso das mídias sociais, destaca-se a falta de mão de obra qualificada, a falta de conhecimento sobre as mídias e a dificuldade em cativar o cliente para interagir com a empresa nas mídias sociais. Ao elaborar este estudo pretendemos compreender e conhecer a evolução e tendências do uso das mídias sociais, nas empresas brasileiras em 2015. Compreender e conhecer estas tendências pode ajudar as empresas a planejar estrategicamente o uso destas ferramentas, usando-as de forma mais eficaz e eficiente.

Este artigo está estruturado da seguinte forma. Primeiro, fazemos uma revisão da literatura sobre as mídias sociais e a sua utilização nas empresas. Segundo, descrevemos a metodologia, participantes e procedimentos usados. Em seguida, apresentamos os resultados. Por fim, discutimos os resultados à luz da literatura e conhecimentos existentes, explicitamos as limitações deste estudo e fazemos sugestões para trabalhos futuros.

\section{REFERENCIAL TEÓRICO}

As redes sociais são fenômenos complexos e recentes nos quais indivíduos e organizações se relacionam em forma de rede. As estruturas das relações sociais estão incorporadas nas ações econômicas dos atores da sociedade (GRANOVETTER, 1985), de tal modo que produtos, parcerias e outras atividades da organização estão sujeitas às influências sociais. Tendências sociais geram impacto no contexto organizacional, portanto, organizações devem estar cientes do contexto social 
em que se situam para que consigam interagir de maneira eficiente com as redes sociais que permeia.

Em resposta à alta quantidade de informações que emergem dos contextos sociais, econômicos e organizacionais, as empresas devem providenciar mecanismos para redução da incerteza e resolução de ambiguidades (EISENHARDT, 1989). Para os gestores, um dos principais problemas não é a falta de informações, já que empresas processam um grande montante de informações, mas sim a falta clareza nessas informações. O conceito de media richness (DAFT e LENGEL, 1986) diz respeito à capacidade de intepretação e aprendizado de uma comunicação. Comunicações ricas não deixam espaço para múltiplas interpretações e dão capacidade de processar mensagens subjetivas e complexas. Portanto, empresas e gestores devem selecionar de quais tipos de mídias que processarão informações (DAFT, LENGEL e TREVINO, 1987; LENGEL e DAFT, 1988).

Meios de comunicação podem ser hierarquizados de acordo com a sua riqueza (DAFT, LENGEL e TREVINO, 1987). Comunicações face-a-face estão no topo da hierarquia de riqueza de mídia, já que permite um feedback rápido e mútuo. Mensagens por ligações telefônicas não são tão ricas como as mensagens face-a-face, pois permitem feedback imediato, mas sinais visuais são perdidos no processo. Na base da hierarquia estão as mensagens escritas, que podem ser endereçadas ou não. Documentos endereçados possuem uma riqueza maior que documentos formais não-endereçados. Ambos possuem a mesma velocidade de feedback e não são capazes de transmitir nenhum sinal visual ou auditivo, mas diferem no quesito da pessoalidade. Mensagens que possuem um destinatário específico são pessoais e mais ricas que mensagens sem destinatários específicos.

Com a importância da inserção das empresas em redes sociais, gestores e dirigentes estão cada vez mais preocupados em como suas empresas podem utilizar de maneira lucrativa aplicativos como Wikipedia, YouTube, Facebook e Twitter. Mídias sociais permitem com que empresas participem e interajam com consumidores de maneira direta, com um custo relativamente baixo e com níveis elevados de eficiência em comparação com ferramentas de comunicação mais tradicionais (KAPLAN e HAENLEIN, 2010). Além de serem mais baratas e mais eficientes, ações de marketing em mídias sociais aumentam o valor da marca de uma empresa (KIM e KO, 2012); e, consequentemente, ajudam a marca a expandir a sua atuação, deixando de ser uma atuação física e regional para um atuação virtual e global (BRUHN, SCHOENMUELLER e SCHAFFER, 2012).

A transformação que as mídias sociais geram na sociedade, de acordo com Berthon, Pitt, Plangger, e Shapiro (2012), pode ser sumarizada em cinco axiomas: (1) mídias sociais são sempre uma função da tecnologia, cultura e governo de um país ou contexto particular; (2) eventos locais 
raramente permanecem locais; (3) eventos globais estão sujeitos a serem interpretados localmente; (4) ações e criações de consumidores criativos também são dependentes da tecnologia, cultura e governo; e (5) a tecnologia possui uma dependência histórica. No cerne destes axiomas está a preocupação de gestores e empresários em se manterem atualizados sobre mídias sociais, tendências tecnológicas e perspectivas dos consumidores. Similarmente, Kietzmann (2011), argumenta que mídias sociais no contexto da administração devem ser abordadas sob sete perspectivas diferentes que possibilitam distinguir e examinar cada faceta da experiência do usuário das mídias sociais e suas implicações para a empresa. As sete perspectivas das mídias sociais (presença, compartilhamento, relações, identidade, conversações, reputação e grupos) não são mutuamente exclusivas, portanto nem todas tem que estar presentes numa atividade típica de mídias sociais. A principal função dessas perspectivas é a possibilidade de perceber os diferentes níveis de funcionalidade em que as mídias sociais podem ser configuradas.

\section{METODOLOGIA}

Esta seção explica os procedimentos metodológicos utilizados neste estudo delphi. Dividimos em duas partes: primeiramente, explicamos o método delphi utilizado no estudo; e na segunda abordamos questões metodológicas referentes a pesquisa, como a criação dos questionários, a escolha dos especialistas e os procedimentos de análise.

\subsection{O MÉTODO DELPHI}

O nome delphi é uma referência ao oráculo de Delfos da Grécia Antiga, que, segundo a mitologia grega, era capaz de prever o futuro (ZACKIEWICZ e SALLES-FILHO, 2001). O método foi desenvolvido na década de 1950 por pesquisadores da Rand Corporation (LINDSTONE e TUROFF, 2002). Inicialmente, o objetivo dos era desenvolver uma técnica para aprimorar o uso da opinião de especialistas quanto a previsão tecnológica (WRIGHT e GIOVINAZZO, 2000), especificamente quanto ao uso de tecnologia militar (KLEINER, 2003).

Delphi é um instrumento para a realização de análises qualitativas e projeções de tendências futuras, tendo como uma de suas principais características a consolidação das opiniões sobre tendências futuras de um determinado assunto por um painel de especialistas (WRIGHT e GIOVINAZZO, 2000). O método tem por distinção três princípios básicos: o anonimato dos 
participantes, evitando a influência de alguns participantes sobre outros, e possíveis constrangimentos quanto a opiniões (CARDOSO ET AL., 2005); o feedback controlado das respostas obtidas pelo grupo, dando aos indivíduos participantes a oportunidade de modificar ou refinar suas opiniões sobre o tema (LINDSTONE e TUROFF, 2002); o tratamento estatístico das respostas, afim de que os participantes possam se posicionar em relação às opiniões do grupo (WRIGHT e GIOVINAZZO, 2000).

Os procedimentos de execução do método iniciam-se de uma série de questionários que circulam repetidamente, sendo respondidos por especialistas com o intuito de se obter respostas sobre de um determinado tema (WRIGHT e GIOVINAZZO, 2000). Primeiramente os especialistas recebem o questionário inicial, e respondem a uma série de questões quantitativas ou qualitativas sobre o tema da pesquisa. As respostas das questões são tabuladas e analisadas estatisticamente, sendo em seguida retornadas aos participantes. Esse processo é repetido até que se obtenha um nível de consenso considerado satisfatório (WRIGHT e GIOVINAZZO, 2000).

Embora o método preveja várias etapas sucessivas de questionários, pode se limitar a duas rodadas as etapas, sem muitas vezes afetar a qualidade da pesquisa (VERGARA, 2005). O uso do método é recomendado quando não se tem informações precisas, quando é muito custoso para obtêlas, ou quando os métodos estimativos tradicionais não são aplicáveis, pois não há parâmetros iniciais de entrada (dados primários) (LINDSTONE e TUROFF, 2002).

\subsection{PARTICIPANTES E PROCEDIMENTOS}

Esta pesquisa é exploratória e qualitativa, pois visa apresentar um cenário prospectivo. Estudos exploratórios permitem aumentar o conhecimento sobre determinado problema, sendo utilizados quando um problema de pesquisa é relativamente novo e se tem poucas informações sobre o assunto. (TRIVINÕS, 1995; COLLIS e HUSSEY, 2005). Mídias sociais é um assunto recente e complexo, por isso, optamos por utilizar do método delphi, que fornece as características necessárias ao estudo proposto.

Utilizamos um processo de consulta em duas fases com um grupo interdisciplinar de doze especialistas. Para contemplar diferentes perspectivas sobre o assunto, a escolha dos especialistas foi composta por indivíduos com diferentes formações em áreas correlatas (TAYLOR e BOGDAN, 1998). Um dos especialistas é fundador de um dos maiores portais de internet do Brasil, outro é considerado um dos maiores especialistas mundiais em mídias sociais. Seis possuem ampla experiência em consultoria de negócios e marketing, são sócios fundadores das empresas em que 
trabalham e atuam, também, como professores em Universidades. Ainda, dois dos participantes são diretores em empresas de grande do ramo farmacêutico e publicidade. Finalmente, dois remanescentes são gerentes de marketing em empresas de grande porte do setor de educação e do varejo.

A pesquisa foi iniciada em 1 de Novembro de 2011 e finalizada em 22 de Dezembro de 2011. Primeiramente, ocorreu a pesquisa inicial sobre o tema mídias sociais nas empresas afim de identificar as dimensões envolvidas no problema da pesquisa e as informações disponíveis sobre o tema. Em seguida, elaboramos as perguntas com base no que foi identificado anteriormente. O questionário foi composto de perguntas abertas e fechadas, sobre os seguintes temas: adoção e utilização pelas empresas, público alvo, tipos e ferramentas em mídias sociais, motivação e conteúdo, setores responsáveis e barreiras e investimento em mídias sociais.

Os especialistas receberam o primeiro questionário finalizado. Com as respostas dos especialistas foram elaboradas as perguntas da segunda consulta, em forma de questão fechada e reordenadas por temas. Posteriormente, foram submetidas aos especialistas em um segundo questionário. Com isso, obteve-se o consenso ou o dissenso sobre cada uma das hipóteses surgidas durante a primeira consulta.

Finalmente, ocorreu a elaboração dos resultados da pesquisa. Recebidas as respostas referentes ao questionário final, ocorreu a seleção das perspectivas aceitáveis (aquelas que receberam ao menos 8 indicações de consenso entre os 12 especialistas), a análise dos resultados, e, por fim, a redação de um cenário contendo os resultados.

\section{APRESENTAÇÃO E ANÁLISE DOS RESULTADOS}

As perspectivas decorrentes das opiniões dos especialistas foram estruturadas na forma de um cenário. A apresentação do cenário decorrente das respostas do especialistas no delphi é divida em tópicos que refletem os temas abordados na pesquisa, sendo estes: 4.1 Adoção e utilização pelas empresas; 4.2 Publico alvo; 4.3 Tipos e ferramentas em mídias sociais; 4.4 Motivação e conteúdo; 4.5 Setores responsáveis e barreiras; e 4.6 Investimentos em mídias sociais.

\subsection{ADOÇÃO E UTILIZAÇÃO PELAS EMPRESAS}

Com a facilidade de acesso as mídias sociais estima-se que praticamente todas as grandes empresas presentes no Brasil irão aderir às mídias sociais até 2015, sendo seguidas por mais da 
metade das empresas de médio porte. $\mathrm{O}$ crescimento do uso das mídias sociais irá assemelhar-se a adoção dos sites corporativos na internet, sendo primeiramente usados por empresas de maior porte, e posteriormente utilizado por empresas menores. As empresas pequenas estarão presentes, mas em menor número que as demais. Segundo um especialista, o principal ponto sobre as empresas de pequeno porte é que:

“... utilizar não significa saber usar este meio para favorecer as empresas. A tendência é que as menores entrem na rede, mas não utilizem de forma correta."

Dentre as principais utilizações das mídias sociais pelas empresas estarão, o uso como canal de venda e como canal de relacionamento no Brasil em 2015. Ainda, setores com maior proximidade com o cliente final terão maior aderência às mídias sociais no Brasil em 2015, sendo que os que irão se destacar no uso intensivo das mesmas serão os seguintes setores: serviços, varejo, mídia e telecom, financeiro, turismo, e imobiliário.

\subsection{PÚBLICO ALVO}

As classes A, B, e C estarão entre as mais abordadas nas mídias sociais pelas empresas no Brasil em 2015, recebendo propostas mais específicas e avançadas. As classes de menor renda, como a D e E, não estarão entre os públicos alvo prioritários das empresas nas mídias sociais, portanto, recebendo propostas menos específicas e mais abrangentes. Ainda assim não deverão ser deixadas de lado como, de acordo com a visão de um especialista:

\footnotetext{
"Se hoje temos pouca penetração de algumas faixas etárias e temos predominância de algumas classes sociais nas mídias sociais, em breve teremos uma penetração total por todas as classes sociais. Em breve teremos uma penetração total por todas as classes sociais. Em algum grau, a grande maioria das pessoas usará alguma plataforma de mídias sociais, como hoje, de algum modo, a grande maioria das pessoas usa telefone celular. No entanto, o tipo de plataforma que cada púbico usará e o tempo que cada pessoa gastará com mídias sociais, tende a variar de público para público."
}

Quanto a idade do público, pessoas de 18 a 44 anos estarão entre os mais atingidos nas mídias sociais pelas empresas, estando os acima de 65 anos entre os menos focados. A questão do uso das novas tecnologias estar associada a indivíduos mais novos, auxilia no entendimento da escolha do publico alvo em mídias sociais por parte das empresas.

Em relação a escolaridade, indivíduos com ensino médio completo até o superior incompleto estarão entre os públicos mais focados pelas empresas nas mídias sociais. Indivíduos com ensino 
superior completo, também não serão menos atingidos, recebendo boa parte da atenção nas mídias sociais. Já aqueles cujo ensino varia do primário completo até o fundamental incompleto não estarão entre os mais focados pelas empresas nas mídias sociais. A população analfabeta ou com até o primário completo, será um dos públicos menos focados. Como escolaridade tem efeito direto na renda, esta é uma explicação plausível do porque a população com menor estudo está entre as menos abordadas pelas empresas nas mídias sociais.

\subsection{TIPOS E FERRAMENTAS EM MÍDIAS SOCIAIS}

As empresas utilizarão as diversas mídias sociais tendo em mente seus distintos públicos alvo, fazendo uso de mídias sociais mais abrangentes e de mídias específicas em ocasiões diferentes. Sendo que em relação ao montante investido, as com maior abrangência tenderão a receber maior montante que as específicas. Abaixo a compreensão de um especialista sobre o assunto:

\footnotetext{
"A tendência é que as empresas foquem mais nas plataformas de mídias sociais que têm mais públicos e quantidade de pessoas... No entanto, como mencionei anteriormente, a segmentação em mídias verticais tende a trazer resultados mais eficientes. Assim, acredito que apesar das plataformas horizontais tenderem a receber o maior montante de investimentos e ações por parte das empresas, as verticais também terão seu espaço. Podemos fazer uma comparação aqui entre televisão aberta horizontal, e televisão a cabo com canais verticais. Apesar do maior investimento ser nos canais horizontais devido à concentração maior de audiência, os canais pagos também alavancam ações interessantíssimas para as empresas que conseguem atingir um público mais específico, nichado. Acredito que a mesma tendência aconteça nas mídias sociais.”
}

Dentre os tipos de mídias sociais, redes sociais estarão entre as mais aproveitadas pelas empresas, sendo muito utilizadas como ferramenta de vendas e relacionamento, comunidades de compartilhamento também estarão entre os tipos de mídias sociais mais utilizadas corporativamente, social bookmarking será utilizado como ferramenta de promoção, e a publicidade em jogos online crescerá no Brasil.

Quanto as ferramentas, o Google + não será uma das ferramentas mais utilizadas pelas empresas, não conseguindo ter alta penetração com a classe C, como foi o caso do Orkut, o seu predecessor no Brasil. O Facebook será uma das ferramentas mais utilizadas em geral, e o YouTube será muito utilizado para divulgação de marca e produtos pelas empresas. Abaixo o discurso de um especialista citando as contribuições acima: 
"Facebook teve um crescimento muito efetivo em 2011 e deve continuar crescendo pelos próximos anos. Será uma ferramenta muito utilizada pelas empresas. O YouTube é a segunda maior ferramenta de busca do mundo e um dos sites com maior audiência no Brasil. As empresas vão utilizar cada vez mais o potencial da ferramenta para divulgar seus produtos e serviços..."

\title{
4.4 MOTIVAÇÃO E CONTEÚDO
}

As principais motivações para a adoção pelas empresas em 2015 no Brasil serão: o fácil acesso as mídias, o uso como ferramenta de relacionamento, o uso para divulgação de campanhas, o uso como canal de atendimento, o acesso ao público, o uso para pesquisa e teste e o uso como ferramenta de venda. O que evidencia a visão de um especialista:

\begin{abstract}
“As empresas vão perceber que as mídias sociais são mais efetivas como ferramenta de relacionamento. Os usuários de redes sociais querem ser ouvidos e, especialmente, tratados com individualidade. Além disso, cada vez mais as empresas serão motivadas a usar as mídias sociais como ferramentas de vendas, visando rentabilizar o relacionamento com seus consumidores."
\end{abstract}

Dentre os tipos de conteúdo de mensagem teremos que as empresas irão fazer maior uso de mensagens com conteúdo relacional, e promocional. Segundo um especialista em 2015, haverá uma imersão desse dois tipos de conteúdos:

“Em 2015, conteúdos promocionais estarão cada vez mais imersos em relacionais, de tal forma que em muitos casos será difícil distinguir. Esta não distinção poderá ser fator de sucesso e será percebida em campanhas de alta eficiência."

Mensagens com conteúdo institucional devem também ser muito utilizadas. Um especialista explica como poderá ser a adoção deste tipo de conteúdo:

"O conteúdo institucional também tende a crescer, mas com estratégias em que a marca se embuta em conteúdos interessantes e relevantes para o público - o branded content. Teremos cada vez menos espaço para ações interruptivas e cada vez mais espaço para diálogo baseado em permissão e relevância."

\subsection{SETORES RESPONSÁ VEIS E BARREIRAS}

Os departamentos já responsáveis nas organizações pelo gerenciamento e investimento em mídias, no caso, os departamentos de marketing e comunicação, serão predominantemente os responsáveis por gerir as mídias sociais. Também, existirá no futuro um cargo específico para o gerenciamento das mesmas, já que as mídias sociais abordam o público de uma maneira 
completamente diferente das mídias já consolidadas. A opinião de um especialista confirma o que foi dito:

\footnotetext{
"vamos observar o surgimento de novas funções de marketing voltadas a estes ambientes, com provável aumento da especialização com o passar do tempo."
}

A formação de grande parte dos profissionais responsáveis por gerir as mídias sociais será em comunicação ou marketing. Justamente pela necessidade do conhecimento de como se comunicar com, e atingir o público alvo das organizações.

O orçamento não estará entre as barreiras ao gerenciamento e uso das mídias sociais pelas corporações. Sendo que as três principais barreiras deverão ser: a falta de mão-de-obra qualificada, a falta de conhecimento específico sobre as mídias, e atrair o cliente a interagir com a empresa pelas mídias sociais. Todas resultantes em algum grau do fato de que, mídias sociais são assunto relativamente novo, com pouco conhecimento estruturado e disseminado, e por isso não disponível facilmente.

\subsection{INVESTIMENTO EM MÍDIAS SOCIAIS}

No Brasil em 2015, surgirão agências especializadas em mídias sociais, o que ocorrerá por se tratar de uma mídia muito nova e específica. Segundo um especialista isso se deve também porque "a estrutura da comunicação é fragmentada e muito mais complexa". Haverá uma maior integração entre empresa e agência na criação e operacionalização dos conteúdos das mídias sociais, conforme explica um especialista:

\footnotetext{
“A relação empresa/agência também tende a passar por uma transformação profunda. Não será possível mais um modelo em que a estratégia das empresas fique na mão das agências, apenas. Será necessário cada vez mais que a inteligência seja compartilhada entre empresa e agência para que as ações deem resultado. Isso é decorrente da mudança de ações de campanha para ações de plataforma contínuas e também da transformação da natureza do relacionamento com o público, que passa da divulgação apenas para o diálogo. Tornara-se impossível para as agências construir e manter conteúdos sem a colaboração efetiva e permanente das empresas."
}

O crescimento do investimento em publicidade em geral no Brasil de acordo com a opinião de um especialista "tende a não ser tão grande como no passado recente, em 2015 poderá chegar a R \$110 bilhões”. Ainda em relação a publicidade no Brasil, os canais de publicidade online terão crescimento maior que canais offline, sendo que o investimento em mídias sociais deverá ser de no máximo 15\% do de publicidade em geral, ficando em 2015 segundo especialistas entre R\$ 6 e 10 bilhões. 


\section{CONSIDERAÇÕES FINAIS}

A finalidade deste artigo foi entender como será a adoção e utilização das mídias sociais pelas empresas no Brasil em 2015. Para este fim, utilizamos o método de pesquisa delphi com a participação de doze especialistas. Utilizamos as respostas dos especialistas para montar um cenário contendo as opiniões dos mesmos sobre o assunto.

Como principais conclusões chegou-se que, praticamente todas as corporações de grande porte, e boa parte das médias empresas estarão presentes em mídias sociais em 2015, sendo que empresas de setores mais próximos ao cliente final terão maior aderência ao uso das mesmas. Que o uso das mídias sociais será principalmente como canal de venda e relacionamento, podendo ser utilizadas também para a divulgação de campanhas, e para pesquisa e teste. Verificou-se ainda quanto ao perfil do público alvo em mídias sociais, que as classes A, B e C estarão entre as mais abordadas, juntamente com indivíduos entre 18 e 44 anos, de escolaridade variando entre ensino médio completo até superior completo. Redes sociais e comunidades de compartilhamento estarão entre os tipos de mídias sociais mais utilizadas pelas empresas, sendo que respectivamente, o Facebook e o YouTube deverão representar tais categorias, estando entre as ferramentas mais utilizadas pelas empresas em 2015 no Brasil. O departamento responsável por gerir as novas mídias será provavelmente o de Marketing ou Comunicação, sendo que existirá um cargo especifico para tal gerenciamento. Orçamento não estará entre as barreiras ao gerenciamento, devendo o investimento em mídias sociais ser até $15 \%$ do investimento geral em publicidade, estando entre 6 e 10 bilhões. As três principais barreiras para as empresas deverão ser: a falta de mão-de-obra qualificada, a falta de conhecimento específico sobre as mídias, e atrair o cliente a interagir com a empresa pelas mídias sociais.

A escolha do método delphi para este estudo ocorreu por causa de suas características e compatibilidade com objeto de estudo, no caso, a utilização das mídias sociais pelas empresas no Brasil em 2015. O mesmo é recomendado quando não se tem informações precisas, e os métodos estimativos tradicionais não são aplicáveis pois os parâmetros iniciais ainda não foram adequadamente estabelecidos (LINDSTONE e TUROFF, 2002). Sendo indicado, para a realização de análises qualitativas e projeções de tendências futuras por um painel de especialistas sobre um determinado assunto (WRIGHT e GIOVINAZZO, 2000).

As principais limitações da pesquisa são as limitações do método em si, que são: amostragem não probabilística, no caso intencional, visando obter a opinião de indivíduos específicos da população; possibilidade da existência de viés pela escolha dos especialistas; 
probabilidade de existir um consenso forçado de opiniões; possibilidade de ambigüidade e viés na elaboração das perguntas dos questionários; e a dependência dos resultados em relação as opiniões emitidas pelos especialistas (MAKRIDAKIS e WHELLRIGHT, 1978; WRIGHT e GIOVINAZZO, 2000).

Como contribuição prática deste trabalho temos o uso do mesmo por empresas, interessadas em como pode evoluir a adoção e utilização das mídias sociais no Brasil. As empresas podem utilizar das opniões e do cenário aqui exposto para posicionarem-se nas mídias sociais e prepararem-se para atender melhor seus públicos-alvo nestas mídias. Ainda, como contribuição teórica este estudo pode auxiliar pesquisadores do assunto na formulação de hipóteses sobre o futuro das mídias sociais, bem como propor arcabouço teórico oara seus estudos.

Como sugestão para trabalhos futuros, propõe-se a utilização de outros métodos de pesquisa, por exemplo, o uso de questionários em determinadas classes sociais para entender o processo de adesão às mídias sociais. Propõe-se também, o uso de pesquisas em larga escala visando entender o momento atual das mídias sociais no Brasil, tanto pelas empresas como pela população em geral.

Vale ressaltar que apesar do uso generalizado das mídias sociais, para realização deste trabalho não se detectou referências relevantes nos principais periódicos da área de administração, tanto nacionais como internacionais. Isto alerta que, de certa forma, existe espaço para a realização de diversos trabalhos, nas mais diversas áreas relacionadas à administração, utilizando mídias sociais como objeto de estudo. 


\section{REFERÊNCIAS}

Berthon, P., Pitt, L.., McCarthy, I., \& Kates, S. (2007). When customers get clever: Managerial approaches to dealing with creative consumers. Business Horizons, 50(1): 39-48.

Berthon, P., Pitt, L., Plangger, K., \& Shapiro, D. (2012). Marketing meets Web 2.0, social media, and creative consumers: Implications for international marketing strategy. Business Horizons, 55(3): 261-271.

Bruhn, M., Schoenmueller, V., \& Schäfer, D. (2012). Are social media replacing traditional media in terms of brand equity creation? Management Research Review, 35(9): 770-790.

Cardoso, L., Abiko, A., Haga, H., \& Inouye, K. (2005). Prospecção de futuro e método delphi: Uma aplicação para a cadeia produtiva da construção habitacional. Ambiente Construido, 5(3): 23-38.

Carrol, D. United Breaks Guitars. Disponível em: <http://www.youtube.com/watch?v=5YGc4zOqozo> Acesso em 20 de Nov. 2011.

Chung, C., \& Austria, K. (2010). Social media gratification and attitude toward social media marketing messages: A study of the effect of social media marketing messages on online shopping value. Proceedings of the Northeast Business \& Economics Association,: 581-586.

Daft, R., \& Lengel, R. (1986). Organizational information requirements, media richness and structural design. Management science, 32(5): 554-571.

Daft, R., Lengel, R., \& Trevino, L. (1987). Message equivocality, media selection, and manager performance: Implications for information systems. MIS Quarterly,: 355-366.

Deloitte (2011). Mídias sociais nas empresas: O relacionamento online com o mercado. Social Media Brasil.

Fournier, S., \& Avery, J. (2011). The uninvited brand. Business Horizons, 54 (3): 193-207.

Glaser, B., \& Strauss, A. (1967). The discovery of grounded theory: Strategies for qualitative research. New York: Aldine Publishing Company.

Granovetter, M. (1985). Economic action and social structure: The problem of embeddedness. American journal of sociology,: 481-510.

Jacobs, I. (2009). The new interaction of social media: Beyond marketing, the popular tools and techniques can also serve as a channel for support. Customer Relationship Management, 13(6): 12. 
Kaplan, A., \& Haenlein, M. (2010). Users of the world, unite! The challenges and opportunities of social media. Business Horizons, 53(1): 59-68.

Kietzmann, J., Hermkens, K., McCarthy, I., \& Silvestre, B. (2011). Social media? Get serious! Understanding the functional building blocks of social media. Business Horizons, 54: 241-251.

Kim, A., \& Ko, E. (2012). Do social media marketing activities enhance customer equity? An empirical study of luxury fashion brand. Journal of Business Research, 65(10): 1480-1486.

Kleiner, A. (2003). Pierre Wack e a "matilha" de executivos. HSM Management. Informação, conhecimento para gestão empresarial. Ano 7, 39(4): julho/agosto.

Kozinets, R., De Valck, K., Wojnicki, A., \& Wilner, S. (2010). Networked narratives: Understanding word of mouth marketing in online communities. Journal of Marketing, 74 (2): 71-89.

Lengel, R., \& Daft, R. (1989). The selection of communication media as an executive skill. The Academy of Management Executive (1987-1989), 225-232.

Linstone, H., \& Turoff, M. (2002). The Delphi method: techniques and applications. London: Addison-Wesley.

Makridakis, S., \& Wheelwright, S. (1978) Interactive forecasting: Univariate and multivariate methods. $2^{\mathrm{a}}$ ed., San Francisco: Holden-Day.

Mangold, W., \& Faulds, D. (2009). Social media: The new hybrid element of the promotion mix. Business Horizons, 52(4): 357-365.

Patel, L. (2010). The rise of social media. $T+D ., 64(7)$ : 60-61.

Porter, M. (1986). Estratégia Competitiva: Técnicas para análise de indústrias e da concorrência. 7 ed., Rio de Janeiro: Campus.

Qualman, E. (2011). Social network users statistics. Disponível em: <http://www.socialnomics.net/2011/08/16/social-network-users-statistics/> Acesso em 20 set. 2011.

Serra, F., Torres, M., \& Torres, A. (2002). Administração Estratégica: conceitos, roteiro prático e casos. Rio de Janeiro: Reichmann \& Affonso.

Strauss, J., \& Frost, R. (2009). E-Marketing. 5 ed., New Jersey: Prentice Hall.

Taylor, S., \& Bogdan, R. (1998). Qualitative research methods. England: Sage Publications. 
Vergara, S. (2005). Métodos de pesquisa em Administração. São Paulo: Editora Atlas.

Weinberg, B., \& Pehlivan, E. (2011). Social spending: managing the social media mix. Business Horizons, 54(3): 275-282.

Wilson, I. (2002). Cenários que levem à ação. HSM Management, São Paulo, 6(32): maio/junho.

Williamson, D. (2011). Disponível em:

<http://www.emarketer.com/\%28S\%28b3ubmtj1q1cutx45kzo34i45\%29\%29/Article.aspx?R=10 07503> Acesso em 1 out 2011.

Wright, J., \& Giovinazzo, R. (2000). Delphi: Uma ferramenta de apoio ao planejamento prospectivo. Caderno de Pesquisa em Administração, 1(12).

Zackiewicz, M., \& Salles-Filho, S. (2001). Technological foresight: Um instrumento para política científica e tecnológica. Parcerias Estratégicas, 10: 144-161.

Recebido: 06/01/2013

Aprovado: 18/02/2013 